\title{
RANCANG BANGUN SISTEM PENGEREMAN OTOMATIS MENGGUNAKAN ARDUINO UNO DAN SENSOR ULTRASONIK
}

\author{
Syah Alam ${ }^{1}$, Gusti Alga Maulana ${ }^{2}$ \\ ${ }^{1}$ Jurusan Teknik Elektro, Universitas Trisakti, DKI Jakarta \\ ${ }^{2}$ Program Studi Teknik Elektro, Universitas 17 Agustus 1945 Jakarta, DKI Jakarta \\ Email: ${ }^{1}$ syah.alam@trisakti.ac.id, ${ }^{2}$ gustialgamaulana@gmail.com
}

\begin{abstract}
Abstrak
Abstrak-Penelitian ini mengusulkan rancang bangun purwarupa mobil dengan sistem pengereman otomatis. Metode yang digunakan adalah menghentikan putaran roda secara bertahap dimulai dari jarak $50 \mathrm{~cm}$ sampai $30 \mathrm{~cm}$ untuk berhenti total menggunakan mikrokontroller arduino uno yang dikoneksikan dengan motor driver L298 dan sensor ultrasonik HC-SR04 sebagai pendeteksi halangan. Dari hasil penelitian yang telah dilakukan telah berhasil dirancang sebuah prototipe mobil degan sistem pengereman sistem otomatis dengan nilai rata rata jarak berhenti terbaik di $28.75 \mathrm{~cm}$ dari target $30 \mathrm{~cm}$ untuk waktu settingan delay $200 \mathrm{~ms}$. Prototipe yang dirancang memiliki nilai rata-rata kesalahan $4.17 \%$ dan dengan tingkat kekauratan $95.83 \%$. Hal ini menunjukkan bahwa prototipe yang dirancang sudah layak diterapkan sebagai system pengereman otomatis.
\end{abstract}

Kata Kunci: Arduino uno, mikrokontroller, motor driver, pengereman, Ultrasonik

\begin{abstract}
This research proposed design $c$. The method used is to stop the wheel rotation gradually starting from a distance of $50 \mathrm{~cm}$ to $30 \mathrm{~cm}$ to stop completely using an arduino uno microcontroller connected with an L298 driver and an HC-SR04 ultrasonik sensor as an obstacle detector. From the measurement result, a line follower robot with an automatic braking system has been successfully designed with the best average stop distance value at $28.75 \mathrm{~cm}$ from the target of $30 \mathrm{~cm}$ with a delay setting of $200 \mathrm{~ms}$. The proposed robot that was designed has an average probabilty of error is $4.17 \%$ with accuracy level of $95.83 \%$. This shows that the prototipe that was designed was feasible to be applied as an automatic braking system .
\end{abstract}

Keywords: Arduino uno, microcontroller, motor driver, braking, Ultrasonik

\section{PENDAHULUAN}

Perkembangan dunia otomotif saat ini semakin meningkat dan canggih, dan semakin banyaknya produksi mobil. Mobil yang nyaman dan memiliki kecepatan dan tenaga yang prima adalah impian dari semua pengguna. Namun seiring dengan semakin tingginya kecepatan suatu kendaraan, maka resiko akan terjadinya kecelakaan juga semakin tinggi.
Berdasarkan data statistik dari organisasi kesehatan dunia (WHO), pembunuh terbesar nomor 3 di dunia adalah kecelakaan di jalan raya (WHO Report, 2001). Tecatat $65 \%$ dari kecelakaan mobil yang terjadi disebabkan oleh kelalaian individu (otsutsuji, H., Kita, H., Xing, J. and Hirai, S., 2017). Kecelakaan paling utama di USA sendiri ternyata mengalihkan perhatian dari jalan, seperti halnya berbicara melalui sambungan telepon, membaca 
pesan, hingga mengemudi sembari makan. Menurut (Cicchino, 2017), The Global Report on Road Safety yang menampilkan angka kecelakaan lalu lintas yang terjadi sepanjang tahun di 180 negara. Tidak mengejutkan memang melihat nama Indonesia berada di daftar ini mengingat banyaknya pengendara di Indonesia yang kerap kali kedapatan melakukan pelanggaran lalu lintas. Faktanya Indonesia menjadi negara ketiga di Asia di bawah Tiongkok dan India dengan total 38.279 total kematian akibat kecelakaan lalu lintas di tahun 2015. Meskipun Indonesia secara data memang menduduki peringkat ketiga namun dilihat dari presentase statistik dari jumlah populasi, Indonesia menduduki peringkat pertama dengan angka kematian 0.015 persen dari jumlah populasi di bawah Tiongkok dengan presentase 0.018 persen dan India 0.017 persen.

Mikrokontroler arduino uno telah banyak dikembangkan untuk keperluan pengendalian dan monitoring jarak jauh baik untuk keperluan keamanan (Rahayu, E.S. and Nurdin, R.A.M.,, 2019) , medis (Alam, S., Hartanto, S. and Pratama, I., 2019) maupun agrikulltur (Alam, S., Tony, H. and Darmawan, I.G.A.,, 2019). Salah satu kelebihan dari mikrokontroller arduino uno adalah harganya yang terjangkau dan mudah dikoneksikan dengan perangkat lain (Javed, 2016).

Kecelakaan merupakan salah satu faktor penyebab kematian terbesar di dunia. Hal ini biasanya disebabkan karena kelalaian individu dalam mengendarai kendaraan. Tidak sedikit dari pengemudi yang mengantuk atau melamun ketika mengemudi sehingga pengemudi tidak menginjak rem pada saat adanya penghalang didepan kendaraan dan menyebabkan terjadinya kecelakaan.Pada penelitian sebelumnya yang dilakukan oleh (Tonara, D.B. and Dinata, Y.M.,, 2016) telah berhasil dirancang prototipe sistem otomatisasi pengereman autonomous dengan menggunakan sensor infra merah, namun kelemahannya adalah prototipe tidak selalu berhenti pada set point dan masih memiliki tingkat kesalahan yang cukup tinggi yaitu $20 \%$. Penelitian ini mengusulkan metode pengereman otomatis yang memiliki tingkat keakuratan yang lebih baik dengan menggunakan mikrokontroller arduino uno yang dikoneksikan dengan sensor ultrasonik jenis HC-SR04 dan motor driver L298. Pengaturan sensitifitas dan delay pada motor driver dilakukan untuk memperoleh jarak yang sesuai dengan yang ditargetkan.

\section{METODE}

Dalam melakukan proses perancangan dilakukan beberapa tahapan antara lain sebagai berikut :

1. Perencanaan desain

Desain awal dapat dibuat baik dalam bentuk gambar skematik sebelum dirancang dalam bentuk hardware agar diperoleh gambaran konsep dari prototipe yang akan dibuat.

2. Perancangan hardware

Perancangan hardware dibuat setelah desain terselesaikan. Perancangan hardware meliputi uji kinerja sensor, mikrokontroler dan motor driver yang digunakan.

3. Pembuatan program

Program dibuat untuk menjalankan prototipe,rancangan program di simulasikan dan jika sudah berhasil dapat langsung di upload kedalam mikrokontroler yang digunakan prototipe.

\section{Pengujian alat}

Pengujian alat dilakukan dengan menempatkan prototipe pada jalur yang telah disiapkan dan memberikan halangan sebagai indikator pengereman. Jarak pengereman yang terbaca oleh sensor akan ditampilkan oleh LCD display. Target jarak pengereman adalah $30 \mathrm{~cm}$ dari halangan.

5. Analisa

Setelah pengujian alat berhasil, kemudian dilanjutkan dengan melakukan analisa keakuratan jarak dari pengereman otomatis. Jarak pengereman yang terbaca oleh sensor dan ditampilkan oleh LCD display dibandingkan dengan jarak pengukuran sebenarnya

Adapun diagaram alir perancangan dari penelitian ini dapat dilihat pada gambar 1. Gambar 1 menunjukkan diagram alir program yang digunakan untuk merancang sistem pengereman otomatis. Tahap awal adalah melakukan pengaturan pada arduino uno agar bekerja sesuai dengan yang ditargetkan, arduino sebagai mikrontrollernya atau otaknya ini dilengkapi dengan sensor dan modul tambahan lainnya yaitu seperti sensor ultrasonik (sebagai pendeteksi jarak), motor driver (pengendali motor dc), LCD (sebagai penampil jarak yang terukur), LED (indikator tambahan). Dalam kondisi prototipe ini di aktifkan maka arduino dan sensornya akan aktif sesuai yang sudah tersetting. Apabila saat prototipe mobil sedang berjalan dan di depan terdeteksi ada penghalang sensor ultrasonik akan membaca jarak tersebut lalu menampilkan pada display dan bila memasuki jarak bahaya/alarm (mobil mulai mengerem secara otomatis dan bertahap sampai jarak untuk berhenti mobil tersebut 
$30 \mathrm{~cm})$. Sistem pencegahan ketika terjadi malfungsi ada 2 kondisi yaitu, kondisi pertama mobil siap jalan namun sensor mengalami kerusakan maka mobil tidak akan bisa jalan, kondisi kedua ketika mobil sudah berjalan namun sensor mengalami kerusakan mobil tetap akan berjalan namun display LCD tidak akan membaca jarak terukur itu artinya pengemudi harus menggunakan rem manual.

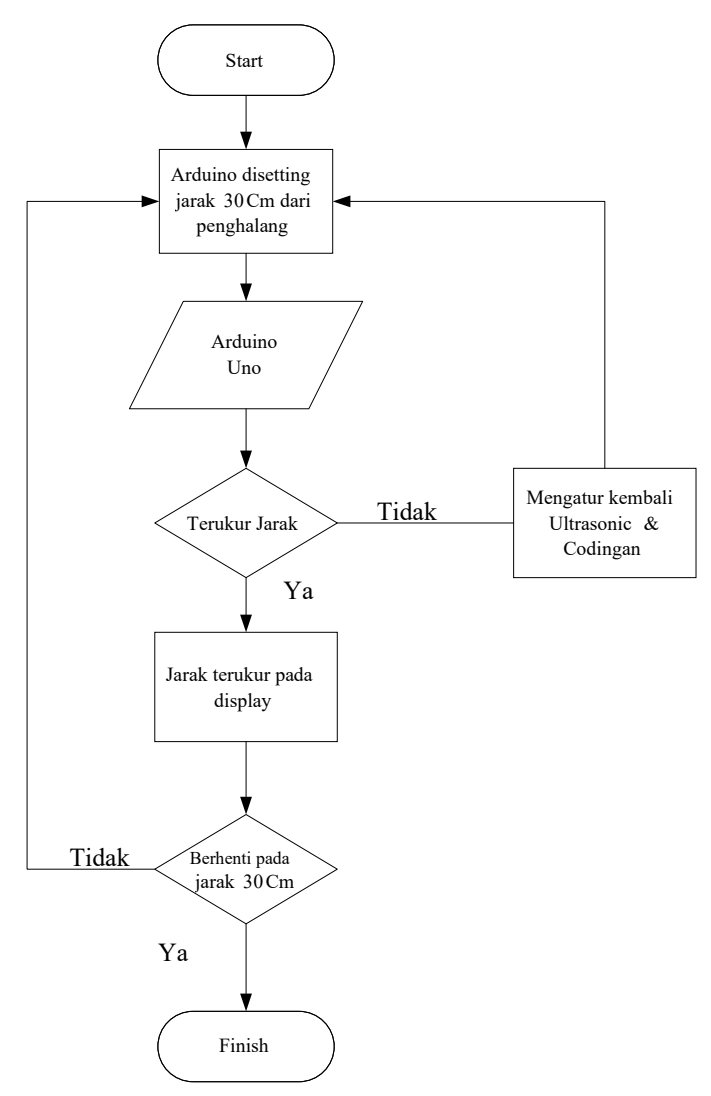

Gambar. 1 Diagram Alir Perancangan

\section{HASIL DAN PEMBAHASAN}

Sebelum melakukan perakitan prototipe, tahapan awal adalah membuat skematik pengawatan / wiring untuk mengetahui hubungan antar komponen yang digunakan. Rancangan skematik system pengerman otomatis ini menggunakan perangkat lunak fritzing, adapun skematik rangkaian system pengereman otomatis dapat dilihat pada Gambar 2.

Gambar 2 menunjukkan sistem wiring rangkaian yang digunakan pada prototipe sistem pengereman otomatis. Prinsip kerja prototipe sistem pengereman otomatis berdasarkan gambar diatas adalah sebagai berikut:

1. Baterai dengan $9 \mathrm{~V}$ memberikan suplai ke motor driver, untuk memberikan input ke motor DC agar motor DC dapat berputar, baterai $9 \mathrm{~V}$ juga digunakan untuk memberikan suplai tegangan ke board arduino sebagai tegangan kerja.

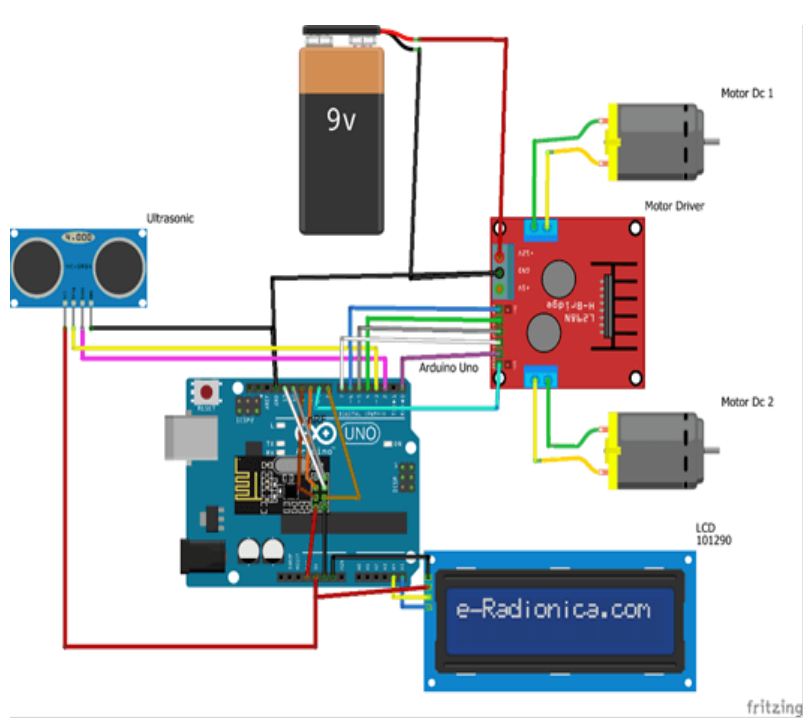

Gambar 2. Skematik Rangkaian

2. Setelah arduino mendapatkan tegangan dari baterai sebesar $9 \mathrm{~V}$, arduino akan memecah tegangan menjadi beberapa tegangan antara lain $3,3 \mathrm{~V}$ dan $5 \mathrm{~V}$. Tegangan sebesar $5 \mathrm{~V}$ digunakan untuk suplai ke LCD, Ultrasonik dan motor driver (untuk kerja IC L298N)

3. Ketika sensor ultrasonik mendapat tegangan sebesar $5 \mathrm{~V}$ maka sensor akan membaca jarak terus menerus, namun ketika sensor ultrasonik membaca jarak dibawah $30 \mathrm{~cm}$ maka LCD akan menampilkan kata "alarm".

4. Ketika motor driver mendapat tegangan sebesar $5 \mathrm{~V}$ maka motor driver akan bekerja, motor driver bekerja juga berdasarkan masukan dari sensor ultrasonik, misalnya bila jarak diatas $50 \mathrm{~cm}$ maka motor dc masih terus berputar kencang namun apabila jarak dibawah $50 \mathrm{~cm}-$ $30 \mathrm{~cm}$ motor dc akan bertahap berhenti.

5. Ketika LCD dan I2C mendapatkan tegangan $5 \mathrm{~V}$ maka LCD akan bekerja, LCD juga bekerja berdasarkan masukan dari sensor ultrasonik dalam membaca jarak misalnya ketika sensor ultrasonik membaca jarak dibawah $30 \mathrm{~cm}$ maka LCD akan menampilkan kata "alarm".

Desain dari protipe mobil dengan system pengereman otomatis dapat dilihat pada gambar 3 dan 4. Untuk memperoleh hasil rancangan yang akurat maka dilakukan pengujian terhadap ketelitian sensor ultrasonik dan fungsi dari motor driver yang akan digunakan. Proses pengujian sensor ultrasonik ditunjukkan pada Gambar 5 dan hasil nya 
dipaparkan pada Tabel I. Untuk pengujian motor driver ditunjukkan pada Gambar 6 dan Tabel II. Pengujian dilakukan dengan mengukur tegangan keluaran dari masing-masing alat dan juga membandingkan dengan hasil pengukuran manual.

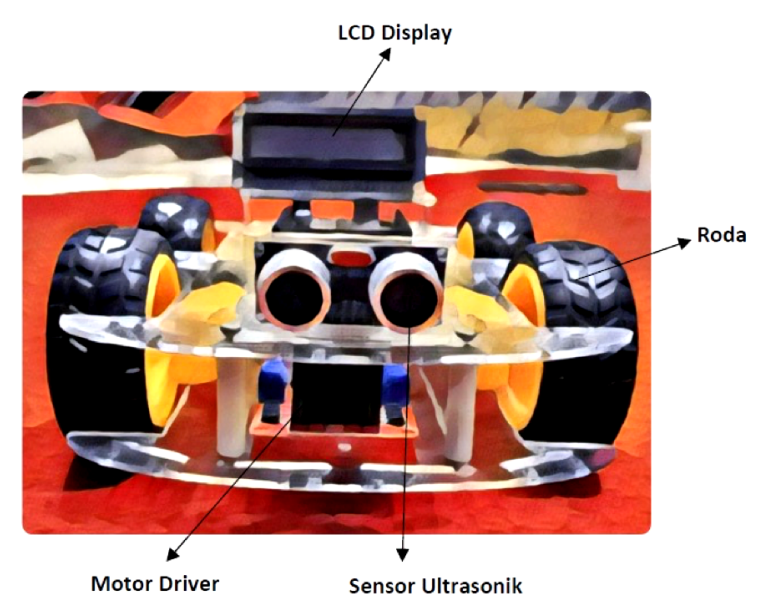

Gambar 3. Desain Tampak depan

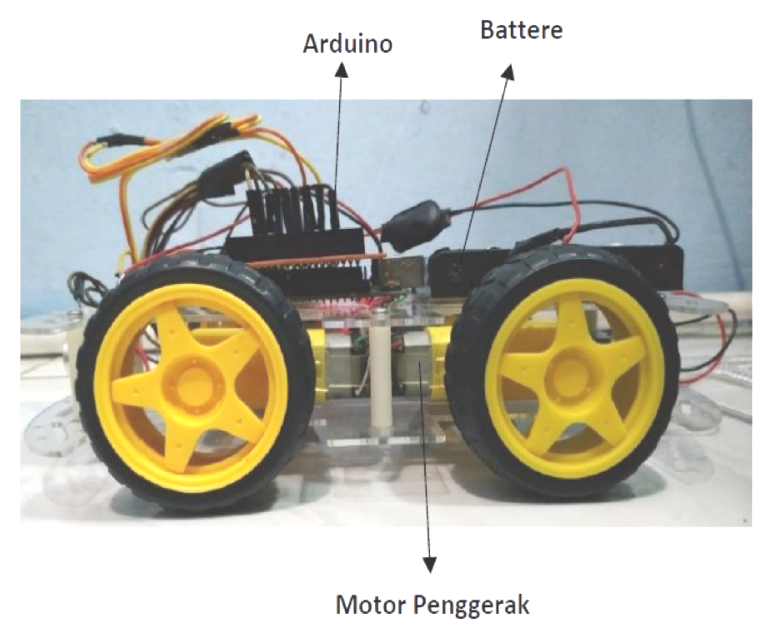

Gambar 4. Desain Tampak Samping

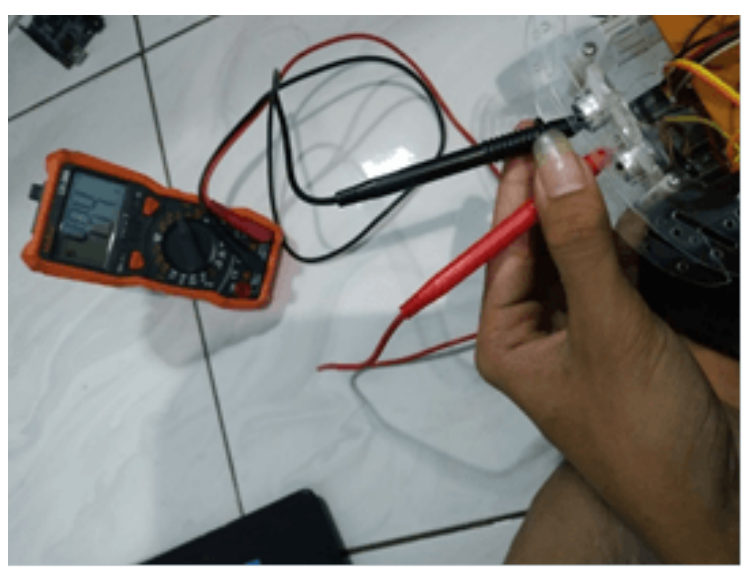

Gambar 5. Pengujian Sensor Ultrasonik
Tabel 1. Hasil Pengujian Sensor Ultrasonik

\begin{tabular}{|l|l|l|}
\hline $\begin{array}{c}\text { Jarak Ukur } \\
\text { Manual }\end{array}$ & \multicolumn{1}{|c|}{$\begin{array}{c}\text { Jarak Ukur } \\
\text { Keluaran Sensor }\end{array}$} & $\begin{array}{c}\text { Tingkat } \\
\text { Kesalahan }\end{array}$ \\
\hline $31 \mathrm{~cm}$ & $33 \mathrm{~cm}$ & $2 \%$ \\
\hline $40 \mathrm{~cm}$ & $40 \mathrm{~cm}$ & $0 \%$ \\
\hline $50 \mathrm{~cm}$ & $51 \mathrm{~cm}$ & $1 \%$ \\
\hline $60 \mathrm{~cm}$ & $60 \mathrm{~cm}$ & $0 \%$ \\
\hline $70 \mathrm{~cm}$ & $68 \mathrm{~cm}$ & $2 \%$ \\
\hline $80 \mathrm{~cm}$ & $78 \mathrm{~cm}$ & $2 \%$ \\
\hline $90 \mathrm{~cm}$ & $89 \mathrm{~cm}$ & $1 \%$ \\
\hline $100 \mathrm{~cm}$ & $98 \mathrm{~cm}$ & $2 \%$ \\
\hline $110 \mathrm{~cm}$ & $108 \mathrm{~cm}$ & $2 \%$ \\
\hline $120 \mathrm{~cm}$ & $117 \mathrm{~cm}$ & $3 \%$ \\
\hline Rata-rata & & $1.5 \%$ \\
\hline
\end{tabular}

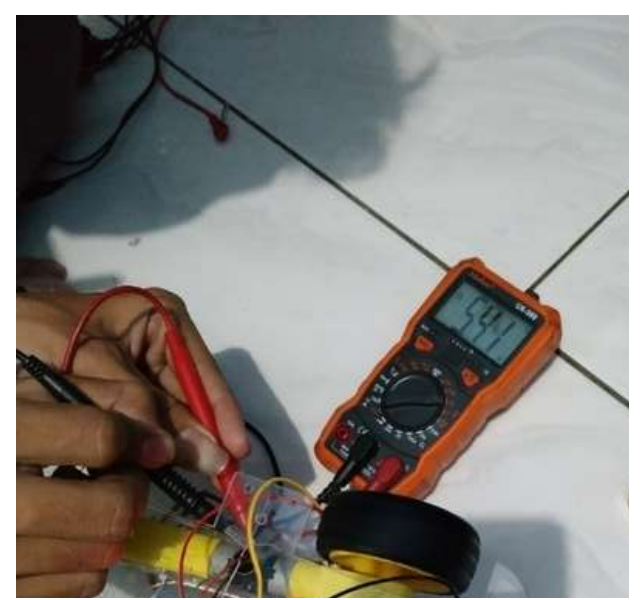

Gambar 6. Pengujian Motor Driver

Tabel 2. Hasil Pengujian Sensor Ultrasonik

\begin{tabular}{|l|l|l|}
\hline Input 1 & Input 2 & \multicolumn{1}{|c|}{$\begin{array}{c}\text { Kondisi } \\
\text { Motor }\end{array}$} \\
\hline LOW & LOW & Motor Mati \\
\hline HIGH & HIGH & $\begin{array}{l}\text { Motor } \\
\text { Bergerak }\end{array}$ \\
\hline
\end{tabular}

Tabel 1 menunjukkan bahwa tingkat kesalahan pembacaan jarak adalah $1.5 \%$ dari 10 kali percobaan. Gambar 6 menunjukkan hasil pengukuran tegangan sebesar $5.41 \mathrm{~V}$ dimana tegangan tersebut di suplai dari motor driver yang digunakan untuk memutar roda. Tabel II menunjukkan logika kerja motor dc dimana pada keadaan HIGH yang ditandai dengan berputarnya kecepatan motor dan dalam keadaan LOW ditandai dengan berhentinya putaran motor.

Setelah melakukan uji kinerja terhadap sensor ultrasonik dan motor driver, tahapan selanjutnya adalah melakukan pemrograman untuk mengontrol 
kinerja dari masing-masing komponen penyusun prototipe. Gambar 7 dan Gambar 8 menunjukkan program yang ditanamkan pada mikrokontroller.

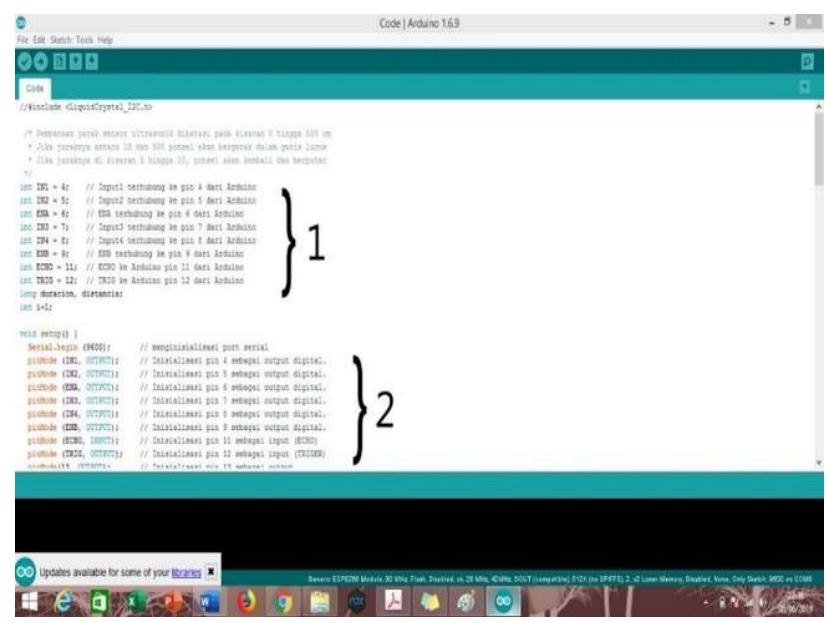

Gambar 7. Program untuk inisialisasi parameter

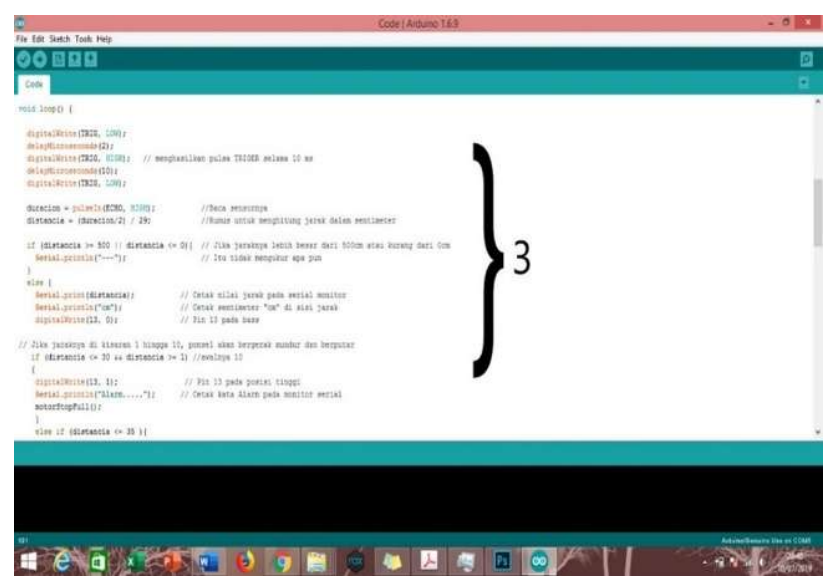

Gambar 8. Program untuk proses looping

Pada Gambar 7, bagian 1 menjelaskan deklarasi awal digunakan untuk mendeskripsikan variabelvariabel yang akan digunakan dalam program utama dan juga untuk menambahkan file-file program yang dibutuhkan untuk menjalankan program utama. Pada bagian 2 dijelaskan setup digunakan untuk menginisiasi variabel, mengatur mode pin pada board, mengatur timer, mengatur baudrate serial port dan sebagainya. Bagian setup hanya dijalankan sekali saja yaitu pada saat awal program dijalankan atau ketika program direset. Gambar 8 bagian 3 menjelaskan bagian loop yang merupakan fungsi utama program yang akan dijalankan berulangulang. Hasil pembacaan sensor ultrasonik yang telah dikoneksikan dengan arduino uno dapat dilihat pada Gambar 9.

Tahapan selanjutnya adalah melakukan uji kinerja prototipe dengan menjalankan prototipe mobil lalu menempatkan halangan di depan nya dengan jarak $30 \mathrm{~cm}$. Pengujian dilakukan sebanyak 10 kali dan diambil nilai rata-rata untuk menghitung tingkat kesalahan dan tingkat keakuratan. Untuk meningkatkan tingkat keakuratan prototipe dilakukan iterasi dengan mengatur nilai delay dari arduino uno. Nilai dan besaran delay yang digunakan adalah $200 \mathrm{~ms}$ dan $400 \mathrm{~ms}$. Hasil pengujian dari prototipe dapat dilihat pada tabel 3 dan Tabel 4.

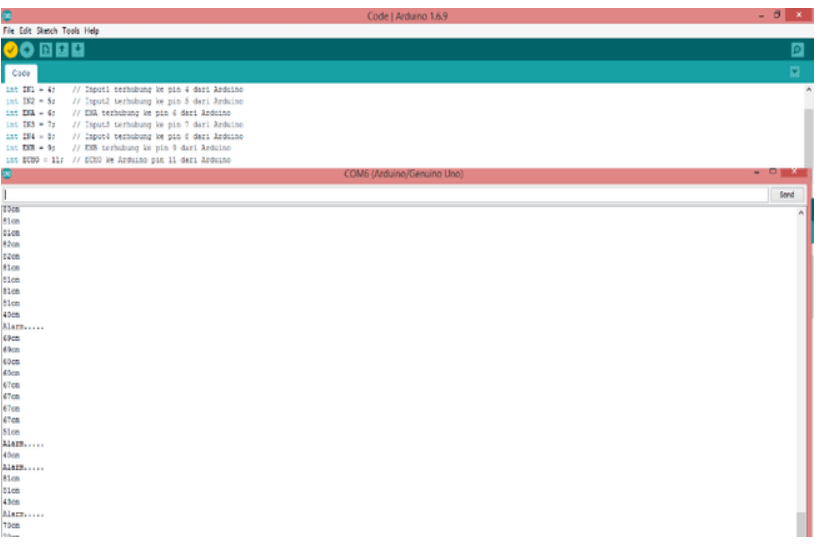

Gambar 10. Hasil Pembacaan Sensor Ultrasonik pada Arduino Uno

Tabel 3. Hasil Pengujian Prototipe pada Delay $200 \mathrm{~ms}$

\begin{tabular}{|l|l|l|l|}
\hline $\begin{array}{c}\text { Jarak Setting } \\
(\mathbf{C m})\end{array}$ & $\begin{array}{c}\text { Jarak Pada } \\
\text { Display (cm) }\end{array}$ & $\begin{array}{c}\text { Jarak Aktual } \\
(\mathbf{c m})\end{array}$ & $\begin{array}{c}\text { Tingkat } \\
\text { Kesalahan }\end{array}$ \\
\hline 30 & 30 & 30 & $0 \%$ \\
\hline 30 & 30 & 29 & $3.3 \%$ \\
\hline 30 & 30 & 29,5 & $1.67 \%$ \\
\hline 30 & 30 & 29 & $3.3 \%$ \\
\hline 30 & 30 & 30 & $0 \%$ \\
\hline 30 & 30 & 28 & $6.67 \%$ \\
\hline 30 & 30 & 27 & $10 \%$ \\
\hline 30 & 30 & 26 & $13.3 \%$ \\
\hline 30 & 30 & 29 & $3.3 \%$ \\
\hline 30 & 30 & 30 & $0 \%$ \\
\hline & Rata-rata & $4.17 \%$ \\
\hline
\end{tabular}

Tabel 4. Hasil Pengujian Prototipe pada Delay $400 \mathrm{~ms}$

\begin{tabular}{|l|l|l|l|}
\hline $\begin{array}{c}\text { Jarak Setting } \\
(\mathbf{C m})\end{array}$ & $\begin{array}{c}\text { Jarak Pada } \\
\text { Display (cm) }\end{array}$ & $\begin{array}{c}\text { Jarak Aktual } \\
(\mathbf{c m})\end{array}$ & $\begin{array}{c}\text { Tingkat } \\
\text { Kesalahan }\end{array}$ \\
\hline 30 & 30 & 22.5 & $25 \%$ \\
\hline 30 & 30 & 24 & $20 \%$ \\
\hline 30 & 30 & 27.5 & $8.3 \%$ \\
\hline 30 & 30 & 18 & $40 \%$ \\
\hline 30 & 30 & 29 & $3.3 \%$ \\
\hline 30 & 30 & 30.5 & $1.67 \%$ \\
\hline 30 & 30 & 30 & $0 \%$ \\
\hline
\end{tabular}




\begin{tabular}{|l|l|l|l|}
\hline $\begin{array}{c}\text { Jarak Setting } \\
(\mathbf{C m})\end{array}$ & $\begin{array}{c}\text { Jarak Pada } \\
\text { Display (cm) }\end{array}$ & $\begin{array}{c}\text { Jarak Aktual } \\
(\mathbf{c m})\end{array}$ & $\begin{array}{c}\text { Tingkat } \\
\text { Kesalahan }\end{array}$ \\
\hline 30 & 30 & 30.5 & $1.67 \%$ \\
\hline 30 & 30 & 30 & $0 \%$ \\
\hline 30 & 30 & 29,5 & $1.67 \%$ \\
\hline \multicolumn{3}{|c|}{ Rata-rata } & $10.17 \%$ \\
\hline
\end{tabular}

Dari Tabel 3 dan Tabel 4 dapat dilihat bahwa tingkat keakuratan prototipe dengan delay $200 \mathrm{~ms}$ jauh lebih baik dibandingkan dengan $400 \mathrm{~ms}$. Hasil perbandingan tingkat kesalahan dari pengaturan kedua delay dapat dilihat pada Gambar 10.

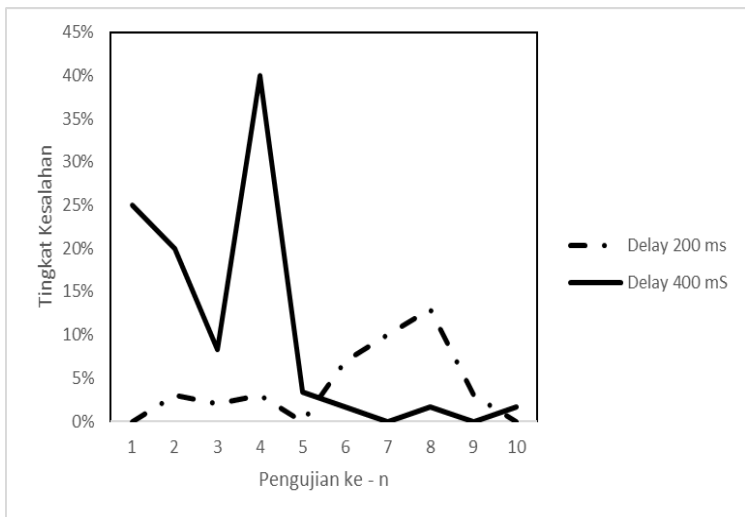

Gambar 10. Perbandingan Tingkat Kesalahan dari Pengaturan Delay

Dari Gambar 10 dapat dilihat bahwa pengaturan delay 200 ms memiliki jarak aktual yang lebih stabil dibandingkan dengan dengan delay 400 ms. Namun pada proses pengujian ditemukan beberapa kekurangan dan kelebihan dari masing-masing pengatuan seperti yang ditunjukkan pada Tabel 5 .

Tabel 5. Kelebihan dan Kekurangan Delay 200 ms Vs $400 \mathrm{~ms}$

\begin{tabular}{|l|l|l|l|}
\hline Kondisi Delay & $\begin{array}{c}\text { Rata-rata } \\
\text { Tingkat } \\
\text { Kesalahan }\end{array}$ & Kekurangan & Kelebihan \\
\hline $200 \mathrm{~ms}$ & $4.17 \%$ & $\begin{array}{l}\text { Jarak berhenti } \\
\text { lebih akurat }\end{array}$ & $\begin{array}{l}\text { Putaran } \\
\text { motor dc } \\
\text { lebih kasar }\end{array}$ \\
\hline $400 \mathrm{~ms}$ & $10.17 \%$ & $\begin{array}{l}\text { Putaran motor } \\
\text { dc lebih halus }\end{array}$ & $\begin{array}{l}\text { Jarak } \\
\text { berhenti } \\
\text { kurang } \\
\text { akurat }\end{array}$ \\
\hline
\end{tabular}

Dari hasil perbandingan pada tabel $\mathrm{V}$, dapat disimpulkan bahwa kondisi delay $200 \mathrm{~ms}$ memiliki kekurangan pada putaran motor yang lebih kasar dibanding $400 \mathrm{~ms}$. Selain itu, untuk memperoleh jarak aktual yang mendekati nilai sebenarnya dapat dilakukan dengan mengatur keadaan berhenti pada jarak $30 \mathrm{~cm}$ untuk tiap pengaturan besaran delay.
Untuk besaran delay $400 \mathrm{~ms}$, diprogram harus diatur dengan jarak $35 \mathrm{~cm}$ artinya terdapat selisih $5 \mathrm{~cm}$ antara program dengan aplikatifnya sedangkan untuk besaran delay $200 \mathrm{~ms}$ keadaan berhenti diatur pada jarak $30 \mathrm{~cm}$ maka pada aplikatifnya akan berhenti pada jarak $30 \mathrm{~cm}$ pula. Dari keseluruhan hasil diatas, penelitian ini telah berhasil merancang dan merealisasikan prototipe sistem pengereman otomatis berbasis arduino uno dengan sensor ultrasonik HC-SR04 dan motor driver L298. Tingkat kesalahan dari prototipe dari 10 kali proses pengujian adalah $4.17 \%$ dengan tingkat keakuratan $98.73 \%$, jauh lebih baik dibandingkan penelitian sebelumnya menggunakan sensor infra merah. Hasil pengujian jarak aktual dapat dilihat pada Gambar 11.

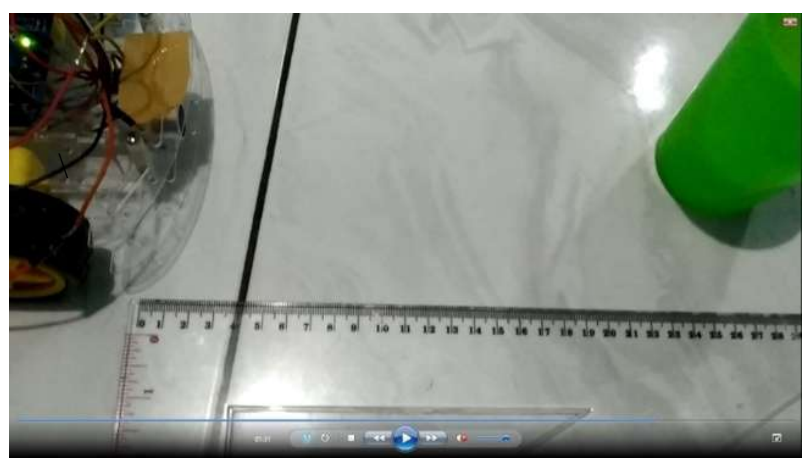

Gambar 11. Pengujian Jarak Aktual Prototipe

\section{PENUTUP}

\section{Kesimpulan}

Robot line follower dengan sistem pengereman otomatis berbasis arduino uno dengan menggunakan sensor ultrasonik HC-SR04 dan motor driver L298 telah berhasil dirancang dan dipaparkan dalam makalah ini. Tingkat kesalahan jarak aktual dapat direduksi dengan melakukan iterasi pengaturan delay pada arduino uno. Dari hasil pengujian sebanyak 10 kali diperoleh besaran delay yang optimal adalah $200 \mathrm{~ms}$ dengan rata-rata tingkat kesalahan $4.17 \%$ dan tingkat keakuratan $98.73 \%$. Dari hasil tersebut, prototipe ini sudah memenuhi kriteria dapar direkomendasikan untuk dapat dikembangkan sebagai sistem pengereman otomatis pada kendaraan mobil .

\section{Saran}

Saran dari penelitian ini adalah pengembangan penelitian ini sebaiknya menggunakan PWM (Pulse Wave Modulation) atau sistem Fuzzy Logic untuk memperoleh putaran motor yang lebih halus. Selain itu perlu diteliti kembali kemampuan dari sensor ultrasonik yang hanya membaca halangan dari sudut yang sangat terbatas. 


\section{Ucapan Terima Kasih}

Penulis mengucapkan terima kasih pada Jurusan Teknik Elektro Universitas Trisakti dan Program Studi Teknik Elektro Universitas 17 Agustus 1945 Jakarta yang telah mendukung terlaksananya kegiatan penelitian ini.

\section{DAFTAR PUSTAKA}

Alam, S., Hartanto, S. AND Pratama, I.,. (2019). RANCANG BANGUN SISTEM MONITORING DETAK JANTUNG MENGGUNAKAN

ELEKTROKARDIOGRAF BERBASIS BLUETOOTH DAN LABVIEW. JTT (JURNAL TEKNOLOGI TERAPAN), 5(2), PP.4755.

Alam, S., Tony, H. and Darmawan, I.G.A.,. (2019). RANCANG BANGUN SISTEM PENYIRAMAN OTOMATIS UNTUK TANAMAN BERBASIS ARUDUINO DAN KELEMBABAN TANAH. JURNAL KAJIAN TEKNIK ELEKTRO, 4(1), pp.4457.

Cicchino, J. (2017). Effectiveness of forward collision warning and autonomous emergency braking systems in reducing front-to-rear crash rates. Accident Analysis \& Prevention, 99, pp.142-152.

Javed, A. (2016). Arduino Basics. In Building Arduino Projects for the Internet of Things. Berkeley, CA: Apress.

otsutsuji, H., Kita, H., Xing, J. and Hirai, S.,. (2017). A car-accident rate index for curved roads: A speed choice-based approach. Transportation research procedia, 25, pp.2108-2118.

Rahayu, E.S. and Nurdin, R.A.M.,. (2019). Perancangan Smart Home Untuk Pengendalian Peralatan Elektronik Dan Pemantauan Keamanan Rumah Berbasis Internet Of Things. Jurnal Teknologi, 6(2), pp.136-148.

Tonara, D.B. and Dinata, Y.M.,. (2016). RANCANG BANGUN AUTONOMOUS BRAKING SYSTEM MENGGUNAKAN SENSOR INFRA MERAH BERBASIS ARDUINO. SESINDO 2016 (pp. 41-50). Surabaya: Departemen Sistem Informasi, Institut Teknologi Sepuluh Nopember. 